\title{
Modeling of the Sedative and Airway Obstruction Effects of Propofol in Patients with Parkinson Disease undergoing Stereotactic Surgery
}

Neus Fábregas, M.D., ${ }^{\star}$ Javier Rapado, Pharm.D., † Pedro L. Gambús, M.D., $\ddagger$ Ricard Valero, M.D., * Enrique Carrero, M.D., Lydia Salvador, M.D., † Miguel A. Nalda-Felipe, M.D.,§ Iñaki F. Trocóniz, Ph.D.\|

\begin{abstract}
Background: Functional stereotactic surgery requires careful titration of sedation since patients with Parkinson disease need to be rapidly awakened for testing. This study reports a population pharmacodynamic model of propofol sedation and airway obstruction in the Parkinson disease population.

Methods: Twenty-one patients with advanced Parkinson disease undergoing functional stereotactic surgery were included in the study and received propofol via target-controlled infusion to achieve an initial steady state concentration of $1 \mu \mathrm{g} / \mathrm{ml}$. Sedation was measured using the Ramsay Sedation Scale. Airway obstruction was measured using a four-category score. Blood samples were drawn for propofol measurement. Individual pharmacokinetic profiles were constructed nonparametrically using linear interpolation. Time course of sedation and respiratory effects were described with population pharmacodynamic models using NONMEM. The probability $(P)$ of a given level of sedation or airway obstruction was related to the estimated effect-site concentration of propofol (Ce) using a logistic regression model.

Results: The concentrations predicted by the target-controlled infusion system generally exceeded the measured concentrations. The estimates of $\mathrm{C}_{50}$ for Ramsay scores 3,4 , and 5 were $0.1,1.02$, and $2.28 \mu \mathrm{g} / \mathrm{ml}$, respectively. For airway obstruction scores 2 and 3 , the estimates of $C_{50}$ were 0.32 and 2.98 $\mu \mathrm{g} / \mathrm{ml}$, respectively. Estimates of $\mathrm{k}_{\mathrm{e} o}$ were 0.24 and $0.51 / \mathrm{min}$ for the sedation and respiratory effects, respectively.

Conclusions: The pharmacokinetic behavior of propofol in patients with Parkinson disease differs with respect to the population from which the model used by the target-controlled infusion device was developed. Based on the results from the final models, a typical steady state plasma propofol concentration of $0.35 \mu \mathrm{g} / \mathrm{ml}$ eliciting a sedation score of 3 with only minimal, if any, airway obstruction has been defined as the therapeutic target.
\end{abstract}

PARKINSON disease (PD) is a highly incapacitating process affecting especially older populations. ${ }^{1}$ The anatomic alteration is located in the neurons of the extrapyramidal system, and the main clinical manifestations are rigidity and tremor. ${ }^{2}$ Besides these neurologic alterations, respiratory dysfunction has been described in

\footnotetext{
${ }^{*}$ Associate Professor, $¥$ Staff Anesthesiologist, § Emeritus Professor, Department of Anesthesiology, Hospital CLINIC, University of Barcelona. † Fellow, || Associate Professor of Biopharmaceutics and Pharmacokinetics, Department of Pharmacy and Pharmaceutical Technology, School of Pharmacy, University of Navarra.

Received from the Department of Anesthesiology, Hospital CLINIC, School of Medicine, University of Barcelona, Barcelona, Spain; and the Department of Pharmacy and Pharmaceutical Technology, School of Pharmacy, University of Navarra, Navarra, Spain. Submitted for publication January 24, 2002. Accepted for publication June 26, 2002. Supported by grant No. 99/0183 from Fondo de Investigaciones Sanitarias, Ministerio de Sanidad, Spain, and by a fellowship award from the University of Navarra, Navarra, Spain (to Dr. Rapado).

Address reprint requests to Dr. Fábregas: Department of Anesthesiology, Hospital CLINIC, Villarroel 170, 08036 Barcelona, Spain. Address electronic mail to: fabregas@medicina.ub.es. Individual article reprints may be purchased through the Journal Web site, www.anesthesiology.org.
}

these patients due to involuntary movements of the glottis and supraglottic structures. ${ }^{3}$

Patients with PD resistant to pharmacologic treatment may have the opportunity to undergo a therapeutic surgical procedure in an advanced stage of their illness. Stereotactic pallidotomy as well as the implantation of electrodes to stimulate selected subthalamic regions can be indicated to improve rigidity and tremor. ${ }^{4}$

Functional stereotactic surgery is performed with local anesthesia, using computed tomography for the mapping of specific trigger points where electric stimulation must be applied to achieve the therapeutic goals. ${ }^{5} \mathrm{~Pa}-$ tients need sedation for this long and sometimes uncomfortable procedure, but they also need to awake rapidly for electrocorticography or neuropsychiatric testing. Since this is an intracranial surgical procedure, access to the head and airway is very limited. In this setting, respiratory depression can quickly become an emergency, and thus sedation must be carefully titrated to avoid oversedation with respiratory depression.

The pharmacokinetics of propofol are characterized by a high hepatic extraction ratio and rapid distribution into peripheral tissues. Plasma concentrations decay rapidly after infusion termination. ${ }^{6-10}$ The pharmacodyamics of propofol are characterized by a clear-headed emergence, rapid return of orientation, and decreased incidence of nausea and vomiting. ${ }^{11,12}$ These pharmacokinetic and pharmacodynamic properties make propofol a suitable anesthetic to be used in patients with PD undergoing functional stereotactic surgery; however, the relation between drug kinetics and depth of sedation in this type of patients has not been characterized.

A constant level of sedation can be achieved by producing a constant propofol concentration in the plasma and biophase. ${ }^{13}$ Target controlled infusion (TCI) systems have been used in clinical and experimental setting since 1981. ${ }^{14}$ TCI systems use specific pharmacokinetic models validated in appropriate populations. ${ }^{15-17}$ Such systems must account for identified pharmacokinetic and pharmacodynamic covariates in the population of interest. ${ }^{18}$

The goal of this study was to model the relation between plasma propofol concentration and sedation or respiratory obstruction in patients with PD undergoing functional stereotactic pallidotomy receiving propofol with the TCI device Diprifusor ${ }^{\circledR}$ (Master TCI, Fresenius Vial S.A., Brezins, France). The pharmacodynamic model was then used to determine the therapeutic propofol 
Table 1. Patient Demographics for the Current Study

\begin{tabular}{|c|c|c|c|c|c|c|}
\hline $\begin{array}{l}\text { Patient } \\
\left(\mathrm{n}^{\circ}\right)\end{array}$ & $\begin{array}{l}\text { Gender } \\
(\mathrm{M} / \mathrm{F})\end{array}$ & $\begin{array}{l}\text { Height } \\
(\mathrm{cm})\end{array}$ & $\begin{array}{c}\text { Age } \\
(y r)\end{array}$ & $\begin{array}{l}\text { Weight } \\
(\mathrm{kg})\end{array}$ & $\begin{array}{l}\text { Duration } \\
\text { (h) }\end{array}$ & $\begin{array}{l}\text { Total Dose } \\
\quad(\mathrm{mg})\end{array}$ \\
\hline 1 & $M$ & 165 & 75 & 65 & 6.88 & 1213 \\
\hline 2 & $M$ & 170 & 43 & 70 & 9.41 & 1260 \\
\hline 3 & $M$ & 156 & 64 & 60 & 5.21 & 507 \\
\hline 4 & $\mathrm{~F}$ & 155 & 67 & 72 & 9.60 & 1082 \\
\hline 5 & $M$ & 167 & 59 & 75 & 5.55 & 792 \\
\hline 6 & $M$ & 155 & 56 & 103 & 6.45 & 1402 \\
\hline 7 & $\mathrm{~F}$ & 150 & 61 & 62 & 5.12 & 702 \\
\hline 8 & $M$ & 168 & 75 & 60 & 10.10 & 1357 \\
\hline 9 & $M$ & 165 & 66 & 61 & 10.12 & 2472 \\
\hline 10 & $\mathrm{~F}$ & 155 & 68 & 83 & 6.72 & 943 \\
\hline 11 & $M$ & 175 & 65 & 70 & 6.48 & 663 \\
\hline 12 & $\mathrm{~F}$ & 155 & 49 & 85 & 9.18 & 1016 \\
\hline 13 & $\mathrm{~F}$ & 148 & 71 & 45 & 8.72 & 322 \\
\hline 14 & $M$ & 155 & 61 & 80 & 8.15 & 604 \\
\hline 15 & $\mathrm{~F}$ & 162 & 62 & 60 & 7.98 & 1192 \\
\hline 16 & $M$ & 149 & 67 & 70 & 0.99 & 282 \\
\hline 17 & $\mathrm{~F}$ & 158 & 70 & 59 & 7.05 & 480 \\
\hline 18 & $\mathrm{~F}$ & 160 & 64 & 72 & 9.04 & 1035 \\
\hline 19 & $M$ & 162 & 69 & 60 & 6.93 & 443 \\
\hline 20 & $M$ & 171 & 46 & 74 & 9.53 & 752 \\
\hline 21 & $M$ & 170 & 65 & 65 & 4.47 & 671 \\
\hline
\end{tabular}

concentration that would keep a patient with PD sedated without inducing dangerous airway obstruction. As a secondary objective we characterized the performance of the pharmacokinetic model used by the Diprifusor $^{\circledR}$ in this subpopulation of patients with PD.

\section{Materials and Methods}

After we obtained institutional review board approval and written informed consent, 21 patients with PD scheduled for stereotactic pallidotomy or implantation of subthalamic nuclei electrodes were enrolled in the study. Patient demographics are summarized in table 1 together with duration and total dose of propofol infused during surgery. All patients were in an advanced stage of a PD resistant to pharmacologic therapy. Prior to surgery, several comedications were administered, all of them related to PD treatment.

\section{Patient Preparation}

All patients were premedicated with $5 \mathrm{mg}$ diazepam administered orally $2 \mathrm{~h}$ before starting the surgery. A stereotactic frame was positioned after infiltration of the scalp with $0.5 \%$ bupivacaine. Afterward, cranial computed tomography was performed. Once the patient arrived in the operating room, a catheter was placed in the radial artery for continuous monitoring of arterial blood pressure and blood sampling. Other monitoring systems included pulse oximetry, continuous expiratory carbon dioxide monitoring, and electrocardiogram. Oxygen administration ( $41 / \mathrm{min}$ ) was provided through nasal prongs. Urine output was measured hourly. Compres- sion stockings were placed in the lower extremities to help venous blood return.

\section{Drug Administration, Blood Sampling, and Pharmacodynamic Measurements}

The target controlled infusion pump (TCI-Diprifusor ${ }^{\circledR}$ ) administered propofol (Diprivan ${ }^{\circledR}$; AstraZeneca, Wilmington, DE) as required by the pharmacokinetic model reported by Marsh et al., ${ }^{16}$ which scales the size of central volume of distribution to the body weight of the patient. The Diprifusor ${ }^{\circledR}$ was programmed to rapidly achieve a propofol plasma concentration of $1 \mu \mathrm{g} / \mathrm{ml}$ in 2 -min duration and then maintain it as required. ${ }^{19,20}$ It was subsequently manually and empirically adjusted to achieve adequate sedation.

Blood samples $(7 \mathrm{ml})$ were drawn every $30 \mathrm{~min}$ from the start of infusion, if at least $10 \mathrm{~min}$ had elapsed since achieving every new target concentration, and also at 1 , $2,3,4,6,8,10,15$, and $20 \mathrm{~min}$ after the infusion was stopped at the end of the surgery. Blood was collected in heparinized tubes and centrifuged at $10,000 \mathrm{rpm}$ for 15 min. Plasma $(4.5 \mathrm{ml})$ was then transferred to polypropylene tubes and stored at $-20^{\circ} \mathrm{C}$ until assayed. Propofol was extracted with percloric-acetonitrile (50:50) after $1 \mathrm{~min}$ of strong agitation. The upper phase $(0.05 \mathrm{ml})$ was analyzed using high-performance liquid chromatography with ultraviolet detection at $251 \mathrm{~nm}$. The mobile phase consisted of acetonitrile, water, and acetic acid (670:329.6:0.4). The limit of detection was $0.075 \mu \mathrm{g} / \mathrm{ml}$, and the coefficient of variation of the assay was $4.12 \%$ for concentrations from 0.1 to $5 \mu \mathrm{g} / \mathrm{ml}$.

Sedation was measured according to Ramsay Sedation Scale. ${ }^{21}$ The degree of airway obstruction was measured 
Table 2. Ramsay Sedation and Airway Obstruction Scores (and their Clinical Meaning) used as Pharmacodynamic End-points

\begin{tabular}{ll}
\hline \multicolumn{1}{c}{ Ramsay Sedation Score } & \multicolumn{1}{c}{ Airway Obstruction Score } \\
\hline $\begin{array}{l}\text { 1. Anxious, agitated and } \\
\text { restless }\end{array}$ & 1. Normal breathing \\
$\begin{array}{ll}\text { 2. Cooperative, orientated, and } \\
\text { tranquil }\end{array}$ & 2. Deep breathing \\
$\begin{array}{l}\text { 3. Response to command only } \\
\text { 4. Brisk response to stimuli }\end{array}$ & $\begin{array}{l}\text { 3. Snoring } \\
\text { 5. Sluggish response to stimuli }\end{array}$ \\
\begin{tabular}{l} 
6. No response \\
\hline
\end{tabular}
\end{tabular}

according to a four-category scale (table 2). Sedation and airway obstruction measurements were performed and recorded $10 \mathrm{~min}$ after each new propofol target level was achieved to ensure that a steady state propofol effect-site concentration was achieved.

\section{Data Analysis}

Pharmacokinetics. The TCI system generated complete records of the infusion rate and predicted plasma and effect-site concentrations of propofol at any time during the study. Those data were used to prospectively evaluate the performance of the model by comparing the predictions with the actual plasma concentrations of propofol at the times that propofol arterial blood samples were drawn.

To evaluate the predictive performance of the Diprifusor ${ }^{\circledR}$ internal pharmacokinetic model, the median performance error [MDPE (\%)] and the median absolute performance error (\%), together with the 95\% confidence interval of MDPE (\%) were computed and used to represent bias and precision respectively. Performance error [PE (\%)] was calculated as:

$$
\mathrm{PE}(\%)=\left(\frac{\text { Cobs }- \text { Cpred }}{\text { Cpred }}\right) \times 100
$$

where $\mathrm{C}_{\text {obs }}$ and $\mathrm{C}_{\text {pred }}$ represent the observed propofol concentrations and the concentrations predicted by the TCI device, respectively. ${ }^{22}$ If the $95 \%$ confidence intervals of MDPE included the zero value, it was concluded that no significant bias was present.

Pharmacodynamics. The probability $(\mathrm{P})$ of a given level of effect (sedation or airway obstruction) was related to plasma propofol concentrations using the following sigmoidal equation:

$$
\mathrm{P}_{\mathrm{ij}}(\text { Effect } \geq \mathrm{m})=\frac{\mathrm{C}_{\mathrm{ij}}^{\gamma_{\mathrm{i}}}}{\mathrm{C}_{\mathrm{ij}}^{\gamma_{\mathrm{i}}}+\mathrm{C}_{50, \mathrm{~m}, \mathrm{i}}^{\gamma_{\mathrm{i}}}}
$$

where $P_{i j}$ (Effect $\geq m$ ) is the probability in the ith individual at that the jth effect score would be equal to or greater than (i.e., "deeper than") a given discrete level $(\mathrm{m}), \mathrm{C}_{\mathrm{ij}}$ is the ith individual concentration of propofol in plasma at jth observation, $\mathrm{C}_{50, \mathrm{~m}, \mathrm{i}}$ is the steady state plasma concentration associated with $50 \%$ probability corresponding to the ith patient, and $\gamma_{\mathrm{i}}$ is the steepness of the probability versus concentration curve corresponding to the ith patient. Interindividual variability was incorporated in the model as follows:

$$
\mathrm{C}_{50 \mathrm{~m}, \mathrm{i}}=\mathrm{C}_{50 \text { pop }, \mathrm{m}} \times \mathrm{e}^{\eta \mathrm{c50, \textrm {m } , \mathrm { i }}}
$$

where $\eta_{\mathrm{C} 50, \mathrm{~m}, \mathrm{i}}$ represents the difference between the typical (mean) population value of $\mathrm{C}_{50, \mathrm{~m}}\left(\mathrm{C}_{50, \text { pop }, \mathrm{m}}\right)$ and the individual specific $\mathrm{C}_{50, \mathrm{~m}}\left(\mathrm{C}_{50, \mathrm{~m}, \mathrm{i}}\right)$. It is assumed that $\eta_{\mathrm{C} 50, \mathrm{~m}}$ is a random variable symmetrically distributed around 0 with variance $\omega^{2}{ }_{\mathrm{C} 50, \mathrm{~m}}$. As implied by equation $3, \mathrm{C}_{50, \mathrm{~m}}$ has a log-normal distribution. During the model development process, the significance of including different interindividual variability terms in $\mathrm{C}_{50}$ and $\gamma$ for each of the sedation or airway obstruction scores was evaluated.

The complete model for each of the two responses studied consisted of three submodels, one for each of the scores: 3, 4, and 5 for sedation and 2, 3, and 4 for airway obstruction, respectively. Sedation score of 2 and airway obstruction score of 1 were not modeled since these are baseline scores when no concentration of propofol was present.

Equation 2 does not predict an effect score directly, but rather predicts the probability of being at or deeper than a particular level. At any given concentration there is a finite probability of being at a particular sedation or airway obstruction score, the sum of those probabilities for all possible scores necessarily being 1 . The probability of being at a particular score as a function of concentration can be calculated as:

$$
\mathrm{P}_{\mathrm{ij}}(\text { Effect }=\mathrm{m})=\mathrm{P}_{\mathrm{ij}}(\text { Effect } \geq \mathrm{m})-\mathrm{P}_{\mathrm{ij}}(\text { Effect } \geq \mathrm{m}+1)
$$

Previous publications have applied the model shown in equation 2 to propofol using effect site concentrations (Ce) rather than plasma propofol concentrations. ${ }^{23,24}$ For this reason we tested a model similar to equation 2 but using $\mathrm{Ce}_{\mathrm{ij}}$. Since there was not a pharmacokinetic model prior to the analysis of the pharmacodynamic responses, the individual propofol plasma concentration-versus-time profiles were generated nonparametrically using linear interpolation. This procedure allowed us to obtain predicted values of $\mathrm{Ce}_{\mathrm{ij}}$ through the estimation of $\mathrm{k}_{\mathrm{e} 0, \mathrm{i}}$, the first-order rate constant governing the distribution from plasma to the biophase in the ith individual, ${ }^{25}$ which was modeled as:

$$
\mathrm{k}_{\mathrm{e} 0, \mathrm{i}}=\mathrm{k}_{\mathrm{e} 0, \mathrm{pop}} \times \mathrm{e}^{\eta \mathrm{ke} 0, \mathrm{i}}
$$

where $\eta_{\mathrm{keO}, \mathrm{i}}$ represents the difference between the typical (mean) population value of $\mathrm{k}_{\mathrm{e} 0}, \mathrm{k}_{\mathrm{eopop}}$, and the individual specific $\mathrm{k}_{\mathrm{e} 0}\left(\mathrm{k}_{\mathrm{e} 0, \mathrm{i}}\right)$. It is assumed that $\eta_{\mathrm{ke} 0}$ is a random variable symmetrically distributed around 0 with variance $\omega_{\mathrm{keO}}^{2}$. 
Table 1 shows five continuous and one categoric (gender) covariates. The effect of these covariates on the parameter estimates was also tested. For example, there is the possibility that as the duration of the surgery (DUR) increases, the potency of propofol decreases (i.e., $\mathrm{C}_{50, \mathrm{~m}}$ increases); this phenomena was modeled as:

$$
\mathrm{C}_{50, \mathrm{~m}, \mathrm{i}}=\mathrm{C}_{50, \mathrm{~m}, \mathrm{pop}} \times\left(1+\theta_{\text {DUR }} \times \mathrm{DUR}_{\mathrm{i}}\right) \times \mathrm{e}^{\eta \mathrm{C}_{50 \mathrm{i}}}
$$

where $\theta_{\text {DUR }}$ is the slope of the $\mathrm{C}_{50, \mathrm{~m}}$ versus DUR curve.

All the population analyses were performed using the Laplacian estimation method with the "likelihood" option as implemented in NONMEM version $\mathrm{V}^{26}$ The results from the population analysis are presented as model estimate, together with the relative standard error, computed as the ratio between the standard error of the estimate and the value of the estimate.

\section{Model Selection}

A model was considered superior to another nested model when the minimum value of the objective function (OBJF) was reduced by 3.88 points. The difference in OBJF between two nested models is approximately chi-square distributed and can be used for significance tests $(P<0.05$, with 1 degree of freedom). For model selection, the OBJF was used together with the visual exploration of the goodness-of-fit plots.

When dealing with continuous variables (i.e., drug concentrations in plasma) the most frequent graphical representations are the observations versus model predictions, residuals versus predictions, etc. One of the problems in analyzing categoric data such as sedation and airway obstruction scores is that model predictions are conditional probabilities of getting a certain score, instead of the observed score itself. Therefore, residual errors could not be calculated and residual plots, a standard analysis tool, could not be constructed.

To evaluate graphically the descriptive performance of the selected population models, a model predictions versus observations type goodness-of-fit plot was developed. The entire range of observed plasma concentrations of propofol was divided in six intervals $(0,>0$ to $\leq 0.2,>0.2$ to $\leq 0.4,>0.4$ to $\leq 0.6,>0.6$ to $\leq 1$, and $>1 \mu \mathrm{g} / \mathrm{ml}$ ). Those intervals were chosen in a way that the number of observed scores within each interval was high enough to compute reliable mean raw data probabilities: $36,74,58,49,66$, and 70 scores for sedation and $36,75,59,49,66$, and 70 scores for airway obstruction, respectively. For each of the concentration intervals, the mean raw data and mean model predicted probabilities of having a certain score " $\mathrm{m}$ " were computed, and the goodness-of-fit plot was constructed plotting the mean model predicted versus the mean raw data probabilities. For each interval, mean raw data probabilities of having a certain score " $\mathrm{m}$ " were calculated as the ratio between the number of observed scores equal to the " $\mathrm{m}$ " score and the total number of observed scores. To obtain model predicted scores, 100 datasets were simulated using the fixed and random effect parameters estimated from the selected population model. Each of the simulated datasets contained the same number of patients, demographic characteristics, design history, and sampling schedule as the original; in addition, the concentrations of propofol in plasma were also the same, since individual pharmacokinetic profiles were created using linear interpolation. Mean model predicted probabilities of having a certain score " $\mathrm{m}$ " were then calculated as the ratio between the number of simulated scores equal to the " $\mathrm{m}$ " score and the total number of simulated scores.

\section{Model Validation}

Case deletion diagnostics or cross-validation was used to detect influential individuals and to explore the robustness of the model. ${ }^{26}$ Cross-validation was performed by refitting the selected model with one patient excluded; therefore, 21 different sets of population parameters were obtained, each of them estimated from 20 individuals. To summarize the results of the case deletion diagnostics, MDPE (\%), median absolute performance error (\%), and the $95 \%$ confidence interval of MDPE (\%) were computed. PE (\%) in this case was calculated as:

$$
\mathrm{PE}(\%)=\frac{\left(\mathrm{P}_{\mathrm{est}}-\mathrm{P}_{\mathrm{CD}}\right)}{\mathrm{P}_{\mathrm{CD}}} \times 100
$$

where $\mathrm{P}_{\mathrm{est}}$ and $\mathrm{P}_{\mathrm{CD}}$ represent parameter (fixed or random) estimates using the original and case deletion datasets, respectively.

\section{Results}

\section{Pharmacokinetics}

The mean duration of propofol infusion was $7.12 \mathrm{~h}$ (range, 0.99-10.12 h). From a total of 355 plasma samples analyzed, 86 showed plasma concentrations of propofol below the limit of quantification, and the range of observed concentrations of propofol in plasma varied from 0.08 to $2.58 \mu \mathrm{g} / \mathrm{ml}$.

Figure 1 shows the individual PE (\%) versus time profiles based on the observed and TCI prediction data, where it can be observed that the majority of the data points lie below the line of zero PE (\%) (line corresponding to a perfect prediction). In this population of patients, the measured propofol concentrations were systematically overpredicted by the TCI device. It should be noted that data with plasma concentrations of propofol below the limit of quantification were not included in the computation of PE (\%). 


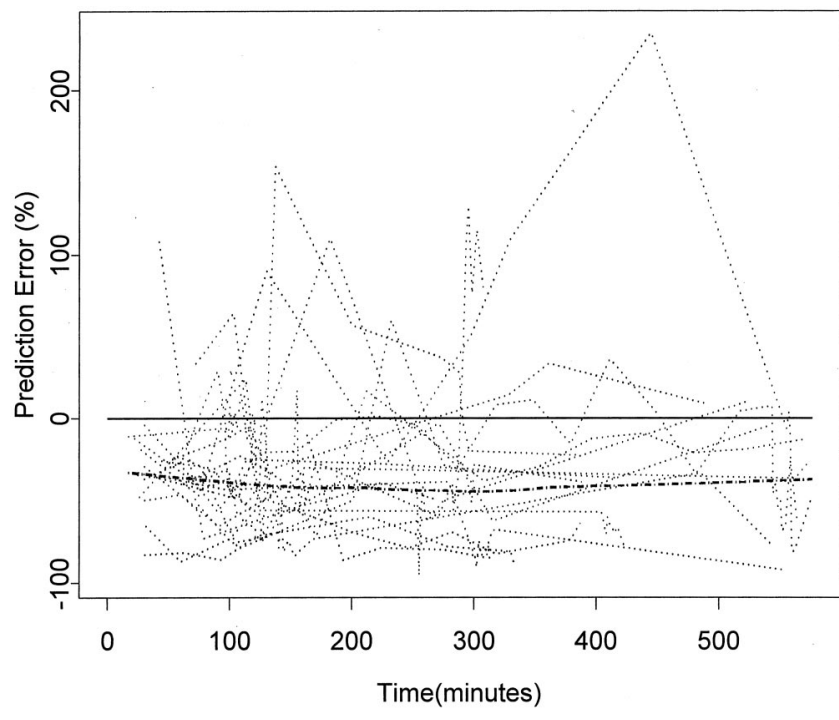

Fig. 1. Individual prediction error versus time profiles. They are computed from the set of parameters reported by Marsh et al. ${ }^{16}$ and used for the TCI system, and the observed propofol plasma concentrations from the current study. The thick solid line represents the $0 \%$ prediction error, and the thick dashed line corresponds to a Loess smoother (S-PLUS 2000; Mathsoft Inc., Seattle, WA) through the data.

\section{Pharmacodynamics}

A total of 356 scores of sedation and 355 scores of airway obstruction were recorded simultaneously to the arterial blood samples. Two measures of sedation were from a patient who was momentarily agitated $(\mathrm{m}=1)$ and were therefore not included in the dataset. Sixteen observations from six patients were from severe respiratory effects $(\mathrm{m}=4)$, but none of the patients in the study were highly sedated $(\mathrm{m}=6)$.

Figure 2 shows the relation between the observed concentrations of propofol in plasma and observed sedation and airway obstruction scores in all individuals. An apparent relation between plasma propofol concentration and effect can be observed. During the linear interpolation process, as a part of the pharmacodynamic analysis, concentrations below the limit of quantification were included in the analysis with a fixed value equal to half the detection limit of the assay $(0.0375 \mu \mathrm{g} / \mathrm{ml})$. Once the population pharmacodynamic model was selected, the effect of this approach on parameter estimation was evaluated by fitting the models to the data using different fixed values for concentrations below the limit of quantification, i.e., 1/1 of the limit of detection of the assay, $1 / 4$ of the limit of detection of the assay, and 1/8 of the limit of detection of the assay. The results remained the same.

The time course of sedation and airway obstruction effects were best described with an $\mathrm{E}_{\max }$ model $(\gamma$, the steepness of the probability $v s$. concentration curve, was not significantly $[P>0.05]$ different from 1$)$ using the effect-site concentrations of propofol as predictor vari-
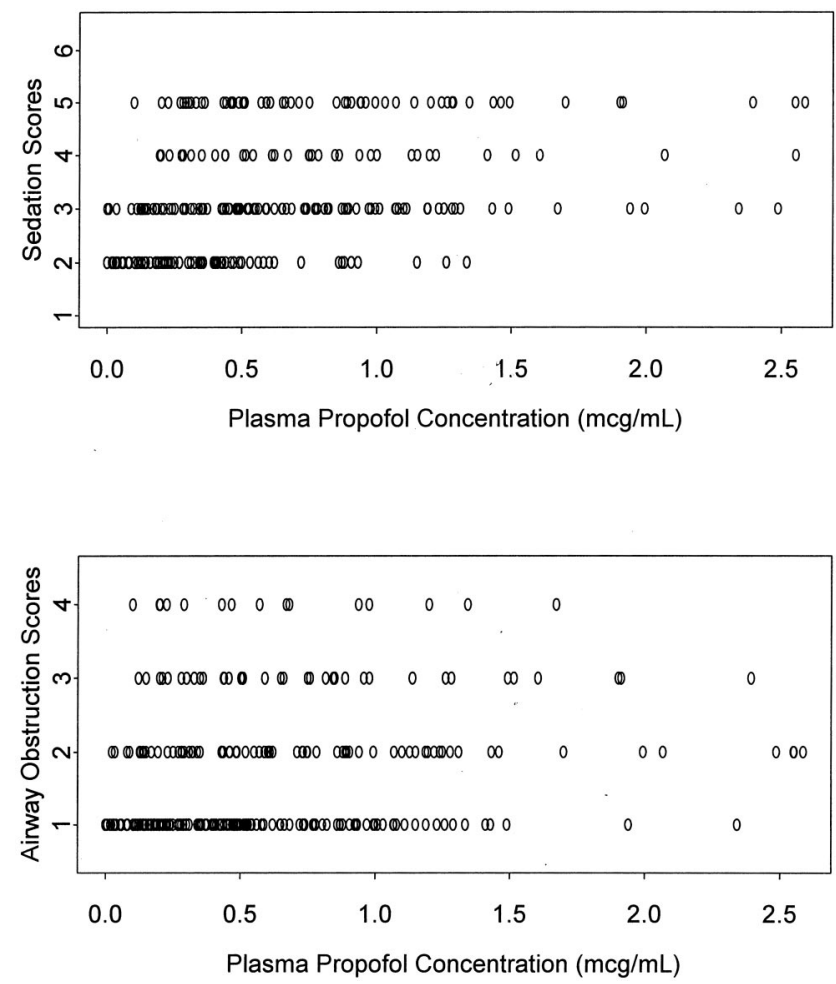

Fig. 2. Description of the raw data. Ramsay sedation scores (top) and airway obstruction scores (bottom) versus observed plasma propofol concentrations.

able. Including the effect-site concentrations instead of plasma propofol concentrations, the decrease in OBJF was highly significant (38 and 25 points for sedation and airway obstruction, respectively; $P<0.001)$. Interpatient variability associated with $\mathrm{C}_{50, \mathrm{~m}}$ was found to be highly significant $(P<0.001)$; however, the data did not support the estimation of different variance terms for each $\mathrm{C}_{50, \mathrm{~m}}$ as well as interindividual variability in $\gamma$ or $\mathrm{k}_{\mathrm{e} 0}$. In addition, none of the individual characteristics showed significant covariate effects $(P>0.05)$. Table 3

Table 3. Summary of the Results of the Final Population Pharmacodynamic Models Selected for Sedation and Airway Obstruction

\section{Parameter} Estimate [RSE]

$$
\begin{aligned}
& \text { Sedation } \\
& \mathrm{k}_{\mathrm{e} 0}(1 \mathrm{~min}) \\
& \mathrm{C}_{50(3)}(\mu \mathrm{g} / \mathrm{ml}) \\
& \mathrm{C}_{50(4)}(\mu \mathrm{g} / \mathrm{ml}) \\
& \mathrm{C}_{50(5)}(\mu \mathrm{g} / \mathrm{ml}) \\
& \text { Interindividual variability } \\
& \text { Airway obstruction } \\
& \mathrm{k}_{\mathrm{e} 0}(1 / \mathrm{min}) \\
& \mathrm{C}_{50(2)}(\mu \mathrm{g} / \mathrm{ml}) \\
& \mathrm{C}_{50}(3)(\mu \mathrm{g} / \mathrm{ml}) \\
& \text { Interindividual variability }
\end{aligned}
$$

$0.10[0.31]$

1.02 [0.28]

2.28 [0.41]

$1.36[0.28]$

0.50 [0.22]

$0.32[0.45]$

$2.98[0.44]$

3.50 [0.27]

$\mathrm{k}_{\mathrm{eO}}=$ first order rate constant describing the removal of the drug from the effect site; $\mathrm{C}_{50(\mathrm{~m})}=$ steady-state propofol plasma concentration associated with $50 \%$ probability of being at least at the "m" score. RSE = relative standard error. See text for details. 

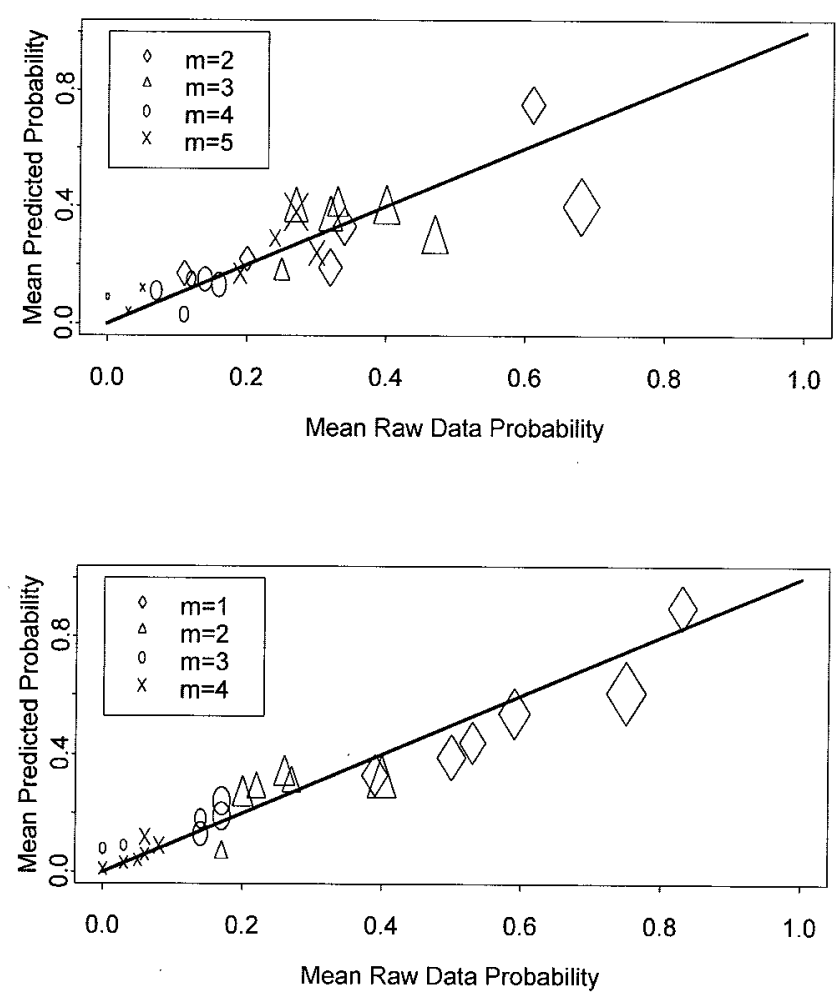

Fig. 3. Mean model predicted versus mean raw data probabilities of having a certain " $\mathrm{m}$ " score for sedation (top) and airway obstruction (bottom). They are computed at specific intervals of steady state plasma concentrations of propofol. The size of each point is proportional to the square root of the number of observations used to compute the mean value. Solid lines represent the line of identity.

lists the final population parameter estimates obtained for sedation and airway obstruction effects. It can be observed that all sedation-related parameters were estimated with adequate precision. The estimate of $\mathrm{C}_{50}$ corresponding to an airway obstruction score of 4 was $24 \mu \mathrm{g} / \mathrm{ml}$ and was considered not reliable since 2.58 $\mu \mathrm{g} / \mathrm{ml}$ was the maximum propofol plasma concentration achieved.

The graphic tool developed to evaluate the descriptive model performance (fig. 3) and the results obtained from the cross-validation shown in table 4 led to the conclusion that the selected population models were supported by the observations.

Figure 3 shows the mean model predicted versus the mean raw data probabilities of having a certain score " $\mathrm{m}$ " for sedation and airway obstruction in each of the predefined propofol concentration intervals. In both parts of figure 3 the number of data pairs is 24 , corresponding to four scores (represented with different symbols) for each of the six concentration intervals. In addition, the number of observations equal to a certain score within each concentration interval has been taken into account, making the size of the symbols proportional to the square root of such number. It can
Table 4. Results of the Case Deletion Diagnostics

\begin{tabular}{lrc}
\hline \multicolumn{1}{c}{ Parameter } & MDPE (\%) [95\%C.I.] & MDAPE (\%) \\
\hline Sedation & & \\
$\mathrm{K}_{\mathrm{e} 0}$ & $-4.08[-8,1]$ & 6.32 \\
$\mathrm{C}_{50(3)}$ & $5.71[-2,9]$ & 7.30 \\
$\mathrm{C}_{50(4)}$ & $0.68[-1,3]$ & 5.77 \\
$\mathrm{C}_{50}(5)$ & $0.82[-2,3]$ & 8.09 \\
Interindividual variability & $-0.26[-3,2]$ & 5.36 \\
Airway Obstruction & & \\
$\mathrm{K}_{\mathrm{eO}}$ & $10.91[-37,59]$ & 11.96 \\
$\mathrm{C}_{50(2)}$ & $-3.98[-27,19]$ & 8.07 \\
$\mathrm{C}_{50(3)}$ & $-0.70[-21,19]$ & 7.55 \\
Interindividual variability & $5.14[-18,28]$ & 7.88 \\
\hline
\end{tabular}

$k_{e 0}=$ first order rate constant describing the removal of drug from the effect site; $\mathrm{C}_{50}(\mathrm{~m})=$ steady-state propofol plasma concentration associated with $50 \%$ probability of being at least at the ' $\mathrm{m}$ ' score; C.I. = confidence interval; MDPE $=$ median of the predicted errors; MDAPE $=$ median of the absolute predicted errors.

be observed that data pairs are randomly distributed around the line of identity, and no trends are apparent as a function of the score or number of observations in the selected concentration intervals. This suggests that the structure of the model selected was appropriate and that no major model assumption violations (i.e., nonsimmetrically distribution of $\eta_{\mathrm{C} 50}$ around 0 ) are present.

The results of the case deletion diagnostics (table 4) show that the population models selected are stable, since none of the 21 individuals was found to be markedly influential on any of the parameters estimated by the models. This can be assessed by the absence of bias and the high precision in the parameters. It is interesting to note that the bias and precision values for $\mathrm{k}_{\mathrm{e} 0}$ were similar to those obtained for the rest of parameters because, due to the quantal nature of the responses and the characteristics of the study design, one would expect a difficult description of the effect site distribution properties. Additional checks, such as fixing the estimate of $\mathrm{k}_{\mathrm{e} 0}$ to previously reported values, ${ }^{18}$ were conducted to further investigate this issue and showed significant $(P<0.05)$ increases in the OBJF values.

The probability curves for discrete levels of sedation and airway obstruction are shown in figure 4 . The steady state plasma propofol concentrations corresponding to the peak probabilities (i.e., probability modes) for sedation scores of 3 and 4 were 0.35 and $1.55 \mu \mathrm{g} / \mathrm{ml}$, respectively, and for airway obstruction scores of 2 and 3 were 0.75 and $8.5 \mu \mathrm{g} / \mathrm{ml}$, respectively. The curves corresponding to sedation scores of 2 and 5 continuously decrease and increase, respectively, as the propofol concentration increases; a similar pattern was observed for airway obstruction scores. The profiles represented in figure 4 show that for a typical steady state propofol plasma concentration of $0.35 \mu \mathrm{g} / \mathrm{ml}$, the probability of adequate level of sedation is maximal with a minimum risk of severe airway obstruction. 

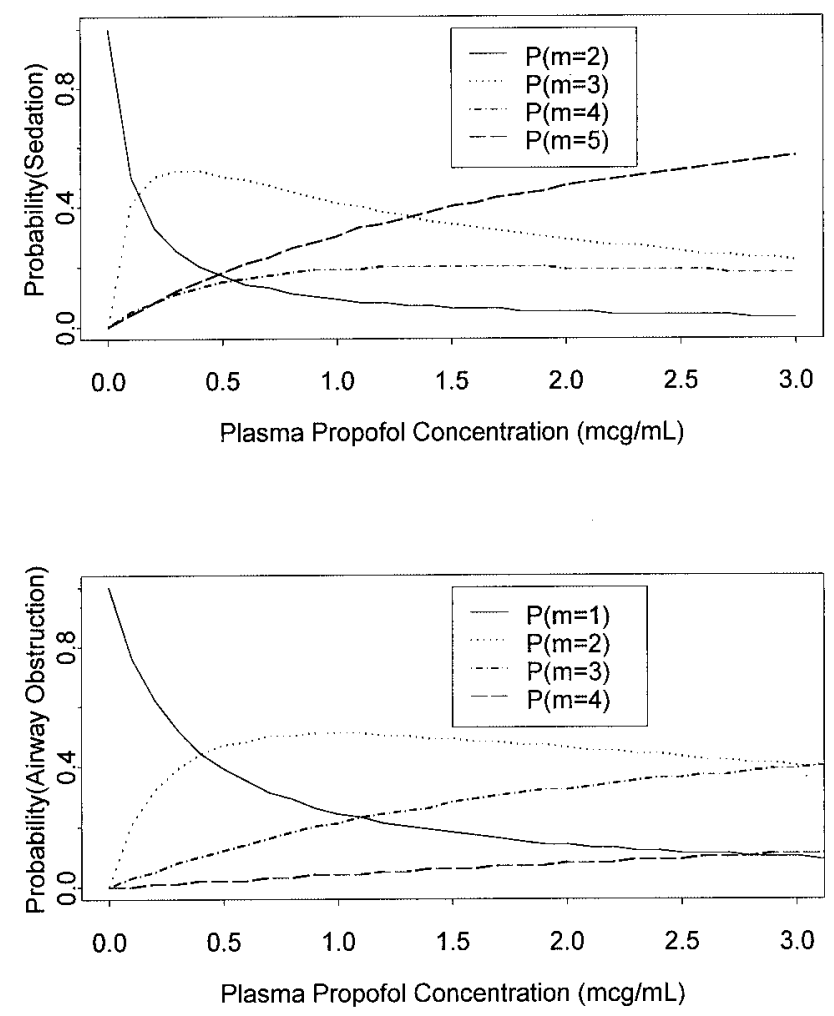

Fig. 4. Probability curves for discrete sedation (top) and airway obstruction (bottom) scores. The peak probability (modes) for each curve corresponds to the steady state plasma concentration of propofol at which a discrete level of response is most likely to occur.

\section{Discussion}

In the current study, a population pharmacodynamic model of sedation and airway obstruction effects, during TCI propofol infusions in patients with PD undergoing stereotactic pallidotomy or implantation of subthalamic nuclei electrodes, is presented. A better understanding of this relation should help clinicians to achieve desired sedation levels without major airway obstruction problems when dealing with this patient population.

A TCI system was used to achieve plasma target propofol concentrations of $1 \mu \mathrm{g} / \mathrm{ml}$. Sedation and airway obstruction effects were measured and modeled as pharmacodynamic variables. Both scoring systems have been used previously by several investigators ${ }^{20,27}$; however, to date, modeling of these effects in PD populations has not been yet performed. Elderly patients are more sensitive to the hypnotic and electroencephalogram measurements of propofol than younger individuals ${ }^{18}$ and patients with certain central nervous system dysfunctions such as PD. Developing safe pharmacologically based sedation schemes can help provide better care to patients with PD.

The TCI system used in the current study implemented the pharmacokinetic model proposed by Marsh et al. ${ }^{16}$ and resulted in a significant overprediction of the observed plasma propofol concentrations. The differences between predicted and observed values could be a result of differences in weight and age found between the two patient populations. The pharmacokinetic profile of propofol seems to be influenced not only by weight, but also by age, height, and lean body mass when it is used as the only anesthetic agent. ${ }^{27}$ Differences in the infusion duration and range of concentrations targeted could also be important, ${ }^{27}$ since it has been suggested that blood clearance of propofol may decrease in long infusions because of a decrease of liver perfusion. Another possibility could be that propofol exhibits different pharmacokinetic characteristics in patients with PD, perhaps because of the concomitant antiparkinsonian medication; however, no data are available on this point. In addition, all of the patients in the population studied by Marsh et al. ${ }^{16}$ received alfentanil; however, such opioid was not used in the current study.

No attempts to model the pharmacokinetic profile were conducted since the design was not adequate for a kinetic study of a drug such as propofol, characterized by a fast distribution and a three-compartment model behavior. The pharmacodynamic analysis was complicated by several problems with the study design. First, the Ramsay scale used to assess sedation has limitations. As an ordered categoric scale, a sedation score of 2 represents a deeper sedation level than a sedation score of 1 . However, 1 represents agitation, whereas 2 represents calm, presumably the baseline. There is no provision in the Ramsay scale for a patient who is sedated yet agitated, although such patients are not uncommon. In addition, a sedation score of 2 may be the true baseline for no drug effect, whereas there were several records in the dataset corresponding to patients with high propofol concentrations who had a sedation score of 2 . A second complication is that mental status naturally changes in the absence of drugs. Most persons alternate from a level of 2 (awake) to 3 (sedated) and 4 (asleep) during the day, especially in long surgical procedures such as the one reported here. It is obvious that the level of sedation is not entirely a function of plasma concentration, as represented in our final pharmacodynamic model. The third and most important limitation of our study is that, because it was conducted in patients during the actual surgical procedure, it was not possible to increase the target levels of propofol without jeopardizing the condition of the patient, as the attendant anesthesiologist had no easy access to the head and the airway of the patient. That is why the design did not explore deep sedation $(\mathrm{m}=6)$ or severe airway obstruction scores $(\mathrm{m}=4)$. Although these were not explored, the study design did permit us to identify a clinically optimal range for sedation without compromising a clear airway structure.

The most popular model used to describe the time course of the drug effect after propofol administration is the effect compartment model. ${ }^{25}$ This model has been previously applied to electroencephalograms ${ }^{28,29}$ and 
was also selected in both pharmacodynamic responses studied in the current study. The estimate of $\mathrm{k}_{\mathrm{eo}}$ for sedation was half the value obtained for airway obstruction $(0.24$ and $0.501 / \mathrm{min}$, respectively) and in the range of the values reported previously by Schnider et al. $(0.4561 / \mathrm{min}) .{ }^{18}$ The final models were rerun fixing the value of $\mathrm{k}_{\mathrm{e} 0}$ to the value reported by Schnider et al. For the case of the sedation, minor changes in the OBJF and parameter estimates were found; however, for respiratory depression, a significant increase in the value of OBJF was seen. This is relevant since Struys et $a l^{30}$ compared different values of $\mathrm{k}_{\mathrm{eo}}$ when using a TCI system to target effect site propofol concentration. Their study demonstrated that the value of $\mathrm{k}_{\mathrm{e} 0}$ reported by Schnider et al. was the one whose time course of effectsite concentration paralleled the best with the actual time course of effect, measured by means of the Bispectral Index of the processed electroencephalogram in most patients.

The estimates obtained for $\mathrm{C}_{50}$ were $0.10,1.02$, and $2.28 \mu \mathrm{g} / \mathrm{ml}$ for sedation levels of 3,4 , and 5, assuming level 2 as baseline. The estimates of $\mathrm{C}_{50}$ reported previously in the literature varied as a function of the pharmacodynamic endpoints studied; values of $0.31 \mu \mathrm{g} / \mathrm{ml}$ were estimated for the ability of propofol to prevent postoperative nausea and vomiting, ${ }^{31}$ and a higher $\mathrm{C}_{50}$ of $1.38 \mu \mathrm{g} / \mathrm{ml}$ was found for the electroencephalogram effects. ${ }^{18}$ The value reported by Wakeling et $a l^{13}$ of $4.5 \mu \mathrm{g} / \mathrm{ml}$ when loss of consciousness was explored could be compared with the concentrations needed in the current study to achieve a score of 6 in the Ramsay scale. However, this value of the scale was not reached during the surgical procedure; therefore, the probability could not be modeled. The estimates of $\mathrm{C}_{50}$ for a sedation score of 5 and an airway obstruction score of 3 are close to the maximum observed propofol plasma concentration; however, we think that the data support those estimates because two of the three parameters of the model are a priori known: $\mathrm{E}_{0}=0$ and $\mathrm{E}_{\mathrm{MAX}}=1$. To further explore this issue, a reparameterized form of the $\mathrm{E}_{\mathrm{MAX}}$ model, proposed for those cases where observed concentrations elicit effects far from $\mathrm{E}_{\mathrm{MAX}},{ }^{32}$ was also fitted to the data, and the derived $\mathrm{C}_{50}$ estimates were identical to those reported in table 3 .

Barr et al. ${ }^{33}$ correlated propofol concentrations to sedation scores, but in mechanically ventilated patients in the intensive care unit. The values of $\mathrm{C}_{50}$ reported were $0.13,0.5,0.74,1.48$, and $2.34 \mu \mathrm{g} / \mathrm{ml}$ for Ramsay sedation scores of $2,3,4,5$, and 6 , respectively. It must be pointed out that, in addition to intubation and mechanical ventilation, some of these patients were receiving opioids as analgesics. Opioids can increase the sedative properties of propofol or alter its pharmacokinetics. Integrating results from the pharmacokinetic and pharmacodynamic analyses, Barr et al. ${ }^{33}$ were able to develop dosing regimens for propofol in patients in the intensive care unit and described interesting features such as the emergence time (i.e., time required for the level of sedation to decrease from 5 to 2 ). This type of information could not be extracted from our results since no kinetic model was proposed; therefore, the pharmacokinetics of propofol in patients with PD with nonconcomitant administration of opioids should be specifically addressed. Because of the consistent overprediction of the model, it can be said that the TCI system is safe for this population in that it will not give the patients a higher plasma concentration than what has been programmed.

In conclusion, a model relating propofol concentration and sedation and airway obstruction has been developed and validated for patients with PD undergoing stereotactic and electrode implantation surgery. Based on the results from the final models, a typical steady state plasma propofol concentration of $0.35 \mu \mathrm{g} / \mathrm{ml}$, eliciting a sedation score of 3 with only minimal, if any, airway obstruction, has been defined as the therapeutic target.

\section{References}

1. Hasegawa K, Kowa H: Autosomal dominant familial Parkinson disease: Older onset of age, and good response to levodopa therapy. Eur Neurol 1997; 38(suppl 1):39-43

2. Easdown LJ, Tessler MJ, Minuk J: Upper airway involvement in Parkinson's disease resulting in postoperative respiratory failure. Can J Anaesth 1995; 42: 344-7

3. De Bruin PFC, De Bruin VMS, Lees AJ, Pride NB: Effects of treatment on airway dynamics and respiratory muscle strength in Parkinson's disease. Am Rev Respir Dis 1993; 148:1576-80

4. Favre J, Taha JM, Nguyen TT, Gildenberg PL, Burchiel KJ: Pallidotomy: A survey of current practice in North America. Neurosurgery 1996; 39:883-90

5. Favre J, Taha JM, Steel T, Burchiel KJ: Anchoring of deep brain stimulation electrodes using a microplate: Technical note. J Neurosurg 1996; 85:1181-3

6. Cockshott ID: Propofol pharmacokinetics and metabolism: An overview. Postgrad Med J 1985; 61:45-50

7. Gepts E, Camu F, Cockshott ID, Douglas EJ: Disposition of propofol administered as constant rate intravenous infusions in humans. Anesth Analg 1987; 66:1256-63

8. Shafer A, Doze VA, Shafer SL, White PF: Pharmacokinetics and pharmacodynamic of propofol infusions during general anesthesia. Anesthesiology 1988; 69:348-56

9. Kirkpatrick T, Cockshott ID, Douglas EJ, Nimmo WS: Pharmacokinetics of propofol (Diprivan) in elderly patients. Br J Anaesth 1988; 60:146-50

10. Morgan DJ, Campbell, Crankshaw DP: Pharmacokinetics of propofol when given by intravenous infusion. Br J Clin Pharmacol 1990; 30:144-8

11. Doze VA, Shafer A, White PF: Propofol-nitrous oxide versus thiopentalisoflurane-nitrous oxide for general anesthesia. ANESTHESIOLOGY 1988; 69:63-71

12. Korttila K, Ostman P, Faure E, Apfelbaum JL, Prunskis J, Ekdawi M, Roizen MF: Randomized comparison of recovery after propofol nitrous oxide versus thiopentone-isoflurane-nitrous oxide anesthesia in patients undergoing ambulatory surgery. Acta Anaesthesiol Scand 1990; 34:400-3

13. Wakeling HG, Zimmerman JB, Howell S, Glass PS: Targeting effect compartment or central compartment concentration of propofol. Anesthesiology 1999; 90:92-7

14. Schwilden $\mathrm{H}$ : A general method for calculating the dosage scheme in linear pharmacokinetics. Eur J Clin Pharmacol 1981; 20:379-86

15. Coetzee JF, Dat D, Glen JB, Wium CA, Boshoff L: Pharmacokinetic model selection for target controlled infusions of propofol: Assessment of three parameter sets. ANESTHESIOLOGY 1995; 82:1328- 45

16. Marsh B, White M, Morton N, Kenny GN: Pharmacokinetic model driven infusion of propofol in children. Br J Anest 1991; 67:41-8

17. Shafer SL, Varvel JR, Aziz N, Scott JC: Pharmacokinetics of fentanyl administered by computer-controlled infusion pump. ANESTHESIOLOGY 1990; 73:1091110

18. Schnider TW, Minto CF, Shafer SL, Gambús PL, Andressen C, Goodale DB, Youngs EJ: The influence of age on propofol pharmacodynamics. ANESTHESIOLOGY 1999; 90:1502-16

19. Shafer SL: Towards optimal intravenous dosing strategies. Semin Anaesth $1993 ; 12: 222-34$

20. Murdoch JA, Kenny GN: Patient-maintained propofol sedation as premed- 
ication in day-case surgery: Assessment of a target-controlled system. Br J Anaest 1999; 82:429-31

21. Ramsay MA, Savege TM, Simpson BR, Goodwin R: Controlled sedation with alphaxalone-alphadolone. BMJ 1974; 2:656-9

22. Varvel JR, Donoho DL, Shafer SL: Measuring the predictive performance of computer-controlled infusion pumps. J Pharm Biopharm 1992; 20:63-93

23. Jonsson EN, Karlsson MO. Xpose: An S-PLUS based population pharmacokinetic/pharmacodynamic model building aid for NONMEM. Comp Meth Prog Biomed 1999; 58:51-64

24. NONMEM Project Group: NONMEM User's Guides. Edited by Beal SL, Sheiner LB: San Francisco, University of California at San Francisco, 1999

25. Sheiner LB, Stanski DR, Vozeh S, Miller RD, Ham J: Simultaneous modeling of pharmacokinetics and pharmacodynamics: Application to d-tubocurarine. Clin Pharmacol Ther 1979; 25:358-71

26. Schnider TW, Gaeta R, Brose R, Minto CF, Gregg KM, Shafer SL: Derivation and cross-validation of pharmacokinetic parameters for computer-controlled infusion of lidocaine in pain therapy. ANESTHESIOLOGY 1996; 84:1043-50

27. Thorpe SJ, Balakrishnan VR, Cook LB: The safety of patient-controlled sedation. Anesthesia 1997; 52:1144-50

28. Bührer M, Maitre PO, Crevoisier C, Stanski DR: Electroencephalographic effects of benzodiazepines II. Pharmacodynamic modeling of the electroencephalographic effects of midazolam and diazepam. Clin Pharmacol Ther 1990; 48: 555-67

29. Hung OR, Varvel JR, Shafer SL, Stanski DR: Thiopental pharmacodynamics II. Quantitation of clinical and electroencephalographic depth of anesthesia. ANESTHESIOLOGY 1992; 77:237-44

30. Struys M, De Smet T, Depoorter B, Versichelen L, Mortier E, Dumortier F, Shafer SL, Rolly G: Comparison of plasma compartment versus two methods for effect compartment-controlled target-controlled infusion for propofol. ANESTHESIOLOGY 2000; 92:399-406

31. Gan TJ, Glass PS, Howell ST, Canada AT, Grant AP, Ginsberg B: Determination of plasma concentrations of propofol associated with $50 \%$ reduction in postoperative nausea. ANESTHESIOLOGY 1997; 87:779-84

32. Schoemaker RC, van Gerven JM, Cohen AF: Estimating potency for EMAXmodel without attaining maximal effects. J Pharmacokinet Biopharm 1998; 26 : 581-93

33. Barr J, Egan TD, Sandoval MF, Zomorodi K, Cohane C, Gambús PL, Shafer SL: Propofol dosing regimens for ICU sedation based upon an integrated pharmacokinetic/pharmacodynamic model. ANESTHESIOLOGY 2001; 95:324-33 